\title{
Knowledge-Based Modeling of Manufacturing Aspects in Structural Optimization Problems
}

\author{
M. Huber ${ }^{1, a}$, Ö. Petersson ${ }^{1, b}, H$. Baier $^{1, c}$ \\ ${ }^{1}$ Institute for Lightweight Structures (LLB) - Technische Universität München \\ Boltzmannstraße 15, 85748 Garching, Germany \\ ahuber@llb.mw.tum.de, ${ }^{b}$ petersson@llb.mw.tum.de, ${ }^{c}$ baier@llb.mw.tum.de
}

\begin{abstract}
Keywords: Reinforced aluminum profiles, design optimization, manufacturing constraints, fuzzy knowledge, genetic algorithm
\end{abstract}

\begin{abstract}
In this paper we present a method for the multidisciplinary optimization of structures including qualitative expert knowledge. In addition to multi objective and discrete tasks, which are solved with a genetic algorithm, mainly expert knowledge and experience is available for certain influences in early design stages. Fuzzy Rule Based Systems (FRBS) provide a powerful tool to model such influences via qualitative human knowledge. Based on this idea, a method for building qualitative, knowledge based models has been developed at the institute and enhanced. As an example, structural components constructed from composite aluminum profiles with embedded continuous reinforcing elements have been optimized.
\end{abstract}

\section{Introduction}

The ultimate performance and cost of automotive and aerospace structures are determined disproportional highly in the early stages of product development [1]. Depending on the field of application, many disciplines may influence an optimal design not only via different load cases, but also by economic considerations. For example, while automotive structures are mainly driven by crash loads and low cost bulk production, aeronautical structures are determined by function, life cycle loads, and small batch manufacturing processes. An optimal design for these structures which meets the requirements of different disciplines can be found by using the methods of multidisciplinary structural optimization [2]. While well known methods such as stochastic optimization algorithms [3], robust design [4], and approximation models [5] are applied in later product development stages, their use in early stages is often limited, especially if disciplines which are part of the product development itself influence the optimal structural design, such as newly developed manufacturing processes.

For common manufacturing processes, broad information is available from test data such as shape distortion [6], producibility [7] and economic aspects. Newly developed manufacturing processes such as aluminum-steel composite extrusion [8] are less well known. Several techniques are used to consider manufacturing processes in structural optimization problems. Computationally expensive numerical models [9] and empirical models from simulation and test data [10] are available for some. All still need an extensive data set to build the approximation model or to validate the simulation code respectively.

To integrate manufacturing influences for which a few or no simulations and tests are available at least in a roughly estimated way Hajela [11], suggests the use of fuzzy logic [12] to include expert knowledge in the model. Natural language is utilized for parameterizations of so called Fuzzy Rule Based Systems (FRBS) and 'if ... then' rules link the input and output parameters. The single input/single output models in [11] were extended to multiple inputs/single output by the authors [13].

In the following sections, knowledge based fuzzy models are described together with the applied knowledge acquisition technique and the influence of the knowledge base. A short description of the utilized genetic algorithm, GAME, is given. This algorithm is applied to optimize structural 
components constructed from composite aluminum profiles with embedded continuous reinforcing elements. Finally the according results are discussed.

\section{Knowledge Based Approximation Models}

Different approximation techniques are well established for several engineering problems [5]. The most common are Response Surface Approximation (RSA), Kriging, and Neural Networks, which depend on large data sets to fit/train the model. Of these three methods, e.g. RSA offers a reasonable ability to consider both physical understanding and prior knowledge of the problem [14] in the building process of the approximation model. Examples can be found in [15]. This ability is useful to improve the quality of the approximation using a limited number of support points.

Fuzzy Rule Based Systems offer this ability by definition. They were originally developed by Zadeh [12] and many Fuzzy Logic based approximation techniques have been subsequently established such as Fuzzy Regression [16], Neuro-Fuzzy Systems, etc. [17]. The basic idea to use FRBS for expert knowledge representation in structural optimization was used by Hajela and Yoo in [11] to build a model for the layup time of a composite wing panel depending on one input parameter. For a detailed description of the 'if ... then' rules refer to [13]. The rules are built by the knowledge engineer after the knowledge acquisition is performed.

Knowledge Acquisition. During the knowledge acquisition phase the input and output parameters of the model and their relations are identified and described by an expert or a group of experts. Afterwards this knowledge is transferred to a proper knowledge representation. An overview of different techniques can be found in [18]. It is important to distinguish between implicit and explicit knowledge. Implicit knowledge is general knowledge about a problem, whereas explicit knowledge contains rules and problem solving strategies. The approach for knowledge acquisition used in this paper is twofold: to gain implicit and explicit knowledge.

First Card or Concept Sorting techniques [19] are used to structure the expert's knowledge. Previously defined objects, experiences, and rules are written on cards and the knowledge expert sorts them into groups. The expert describes what each group has in common so they can be hierarchically organized. This method is more efficient than the commonly used protocol analysis [19].

From the Card Sorting results, a structured interview [18] can be derived to develop the rule base of the FRBS by the knowledge engineer. Card sorting and the structured interviews can be easily supported by graphical user interfaces in, for example, EXCEL ${ }^{\circledR}$ or MATLAB ${ }^{\circledR}$.

As an example, different events were found for the extrusion process of composite aluminum profiles with embedded continuous reinforcing elements. They are listed in Table 1. A more detailed description of this manufacturing technique is given for the example later.

\begin{tabular}{|l|l|}
\hline \multicolumn{1}{|c|}{ Event } & \multicolumn{1}{c|}{$\begin{array}{c}\text { Effects on } \\
\text { Structural Properties }\end{array}$} \\
\hline \hline residual stresses in profile after extrusion & $\sigma_{\text {Allowed }}$, suitability for subsequent manufacturing steps \\
\hline $\begin{array}{l}\text { debonding - loss of adhesion between } \\
\text { fibres and base material }\end{array}$ & $\sigma_{\text {Allowed }}$, reject due to defects \\
\hline deformation of profile cross section & cross section area, section modulus, tolerances \\
\hline profile contour deviation due to gravity & overall geometry, tolerances \\
\hline torsion of the profile & overall geometry, tolerances \\
\hline
\end{tabular}

Table 1: Events for the extrusion process of composite aluminum profiles with embedded continuous reinforcing elements 
The following parameters for the event residual stresses in profile after extrusion are hierarchically ordered by their importance.

\begin{tabular}{|l|c|l|}
\hline \multicolumn{3}{|c|}{ residual stresses in profile after extrusion } \\
\multicolumn{1}{|c|}{ Parameter } & Hierarchy & Design Variable in Struct. Opt. \\
\hline \hline cooling conditions & very high & no \\
\hline welding chamber geometry & high & yes, profile cross section \\
\hline number of reinforcing elements & above average & yes, reinforcing ratio \\
\hline contour of the profile & average & yes, topology of structure \\
\hline base material & average & yes \\
\hline reinforcement material & below average & yes \\
\hline reinforcement coating & low & no \\
\hline reinforcement configuration & very low & yes \\
\hline
\end{tabular}

Table 2: Parameters for one event

For calculating the local residual stresses, $\sigma_{\text {residual }}$, for a certain material combination and cross section a simulation model is under development but not yet available. From the knowledge gained by knowledge acquisition, a qualitative performance number $P M_{\text {res }}$ can be approximated. From the parameters in Table 2, a structured interview is derived, which is used to establish the rule base of the Fuzzy Rule Based System. The first parameter has no equivalent design variable in a structural optimization problem and can be neglected, because optimal cooling settings will be used always. The second parameter, welding chamber geometry, depends on the profile cross section. The third parameter, number of reinforcing elements, is directly related to the reinforcement ratio. The contour of the profile is changed only in topology optimization of the overall structure. The base and reinforcement material can be described by discrete design variables. The last two parameters, reinforcement coating, and reinforcement configuration, have only small influences because they are often fixed due to process reliability. A detailed model for $P M_{r e s}$ is described in the example.

\section{Structural Optimization of Composite Vehicle Space Frame Profile}

A composite aluminum profile with embedded continuous reinforcing elements from the generic motorcycle space frame, shown in Fig. 1, was optimized with regard to mass and deformation. In addition to the geometric cross section parameters in Fig. 1, the material combination, and the reinforcing ratios, $f_{1}$ (horizontal outer section), and $f_{2}$ (vertical outer section) were changed. This can lead to large thermal stresses because the stiffeners are not reinforced. A detailed description of the design variables is given in Table 3. 


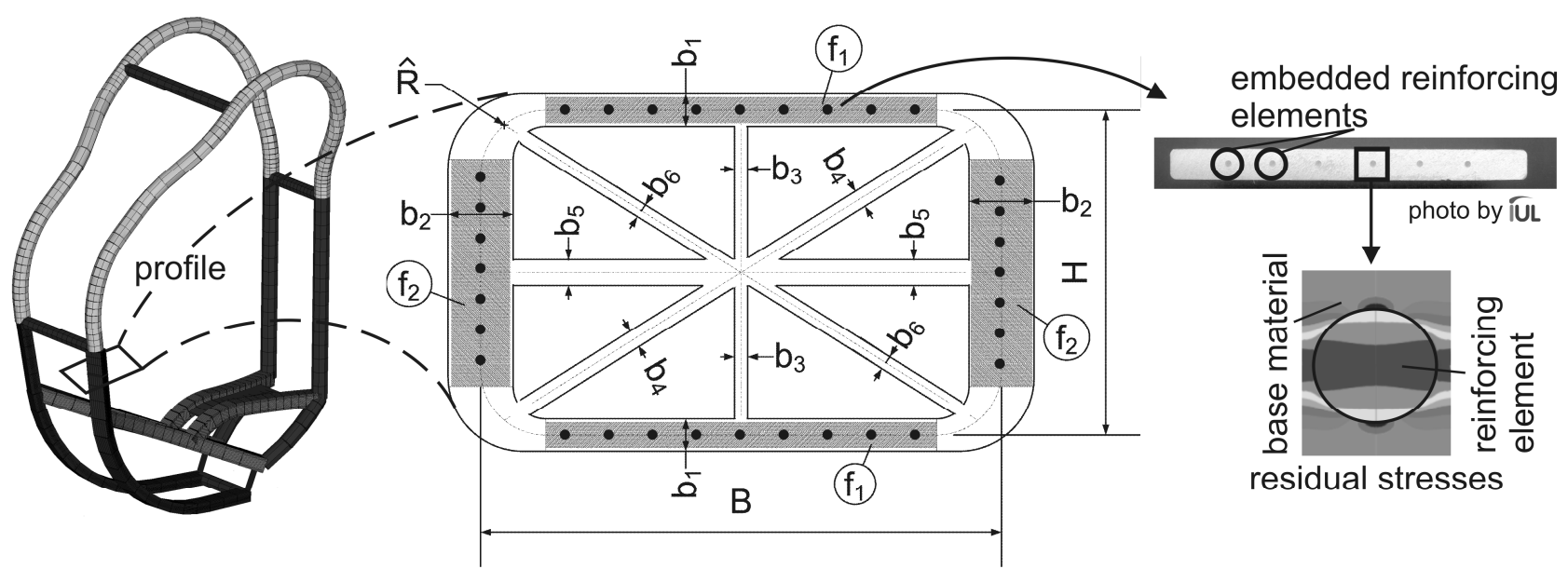

Fig. 1: Geometry parameters of the reinforced profile

\begin{tabular}{|c|c|c|c|c|c|}
\hline Parameter & Description & $\begin{array}{l}\text { Lower } \\
\text { Bound. }\end{array}$ & $\begin{array}{l}\text { Upper } \\
\text { Bound. }\end{array}$ & Step Size & Type \\
\hline$R$ & radius ratio $^{1}$ & 0 & 1 & & continuous \\
\hline$H$ & height & $15 \mathrm{~mm}$ & $100 \mathrm{~mm}$ & & continuous \\
\hline$B$ & width & $15 \mathrm{~mm}$ & $100 \mathrm{~mm}$ & & continuous \\
\hline$b_{1 \ldots 2}$ & wall thickness outer section & $2 \mathrm{~mm}$ & $10 \mathrm{~mm}$ & & continuous \\
\hline$b_{3 \ldots 6}$ & wall thickness stiffener ${ }^{2}$ & $0 \mathrm{~mm}$ & $3 \mathrm{~mm}$ & & continuous \\
\hline$f_{1 \ldots 2}$ & reinforcement ratios & $0 \%$ & $30 \%$ & & continuous \\
\hline$M$ & material combination $^{3}$ & 1 & 4 & $\begin{array}{l}\text { AlSt, AlCF, } \\
\text { MgSt, MgCF }\end{array}$ & discrete \\
\hline \multicolumn{6}{|c|}{$\begin{array}{l}{ }^{1} \text { this is only a ratio: } R=0 \rightarrow \hat{R}_{\min } \text { and } R=1 \rightarrow \hat{R}_{\max } \hat{R}_{\min } \text { and } \hat{R}_{\max } \text { predefined by } H, B \text { and finite } \\
\text { element discretization } \\
{ }^{2} \text { if } \leq 1.5 \mathrm{~mm} \text { the stiffener does not exist } \\
{ }^{3} \mathrm{Al}: \mathrm{Al} 6060 \mathrm{~T} 4, \mathrm{Mg}: \mathrm{AZ} 31 \mathrm{HP}, \text { St: steel wire } 1.4310, \mathrm{CF} \text { : Thornel } 25\end{array}$} \\
\hline
\end{tabular}

Table 3: Design variables of the profile optimization problem

Because of the newly developed curved profile extrusion [20] for reinforced hollow profiles, a heat treatment after the extrusion to minimize residual stresses is not possible since the intended curved shape would deform. The reinforcement induces additional high local residual stresses in the profile, which can lead to problems in subsequent production processes, such as drilling, milling, and joining. A second optimization is performed and a qualitative performance index for the residual stresses $P M_{\text {res }}$ is introduced as third goal to be minimized.

The formulation for the first optimization problem is:

$\min \vec{z}_{1}(\vec{x})=\vec{f}(\vec{x})=[\operatorname{Mass}(\vec{x})$, Deflection $(\vec{x})]$.

such that $g_{1 i} \leq 0 ; \quad i=1 \ldots 16$.

The formulation for the second optimization problem is:

$\min \vec{z}_{2}(\vec{x})=\vec{f}(\vec{x})=\left[\operatorname{Mass}(\vec{x}), \operatorname{Deflection}(\vec{x}), P M_{r e s}(\vec{x})\right]$. 
such that $g_{2 i} \leq 0 ; \quad i=1 \ldots 16$.

The constraints $g_{1 i}=g_{2 i}$ are described later in detail.

Load Cases. The three static load cases computed are listed in Table 4 (support according to Fig. 2). Load cases 1 and 2 refer to a typical loading condition during normal use. The third load case considers the different coefficients of thermal expansion in sections with reinforcement ratio $f_{1}, f_{2}$, and the base material. For each load case a linear buckling analysis is performed to ensure the stability of the lightweight profile and the first eigenfrequency is calculated by modal analysis.

\begin{tabular}{|c|l|l|l|}
\hline LC Nr. & \multicolumn{1}{|c|}{ Description } & \multicolumn{1}{|c|}{ Load } & Support \\
\hline \hline 1 & pothole - driver standing & $\begin{array}{l}F_{L C 1}=2.94 \mathrm{kN} \\
M_{L C 1}=220.50 \mathrm{Nm}\end{array}$ & tread \\
& & tread \\
\hline 2 & pothole - driver seated & $\begin{array}{l}F_{L C 2}=0.74 \mathrm{kN} \\
M_{L C 2}=1102.50 \mathrm{Nm}\end{array}$ & tread \\
& & support 2 \\
\hline 3 & temperature difference & $\Delta T=100.00 \mathrm{~K}$ & - \\
\hline
\end{tabular}

Table 4: Load cases

Constraints. The sixteen constraints consider the stresses both in line and perpendicular to the direction of the embedded continuous reinforcing elements for the three load cases $\left(\sigma_{i \|}, \sigma_{i \perp}, \sigma_{i, \text { Allowed }}\right.$ depends on material combination $M$ and reinforcement ratio $f_{i}$ ), the linear buckling ( $\lambda_{i}$, a safety factor of 50 was chosen after comparison with nonlinear results), the overall deformation of support 2 in load case $1\left(u_{L F 1}, \max . \sim 7.5 \sim \mathrm{mm}\right)$, and the first eigenfrequency $\left(\omega_{1}\right.$, $\min .40 \mathrm{~Hz}$ ). Also, the differences of the wall thicknesses in the single parts of the cross section should be small $\left(b_{x} / b_{y} \leq 3\right.$, five combinations considered).

Finite Element Model. The finite element model (ANSYs ${ }^{\circledR}$ ) with the supports of the profile is displayed in Fig. 2. The tread for the driver on the left side of the profile is used for loading support. The wide range of design variables leads to finite element models with different numbers of elements. This effect is reduced by an automatic element size calculation based on the cross section geometry. A study performed for approximately 1800, 2000, 4000 and 8000 elements on one profile showed negligible effects on the maximum stresses and a minor increase in deformation as expected. During optimization the element number varied between 3792 and 5216 elements. The reinforcement was modeled via homogenized material constants, both in and perpendicular to the direction of the continuous reinforcing elements. 


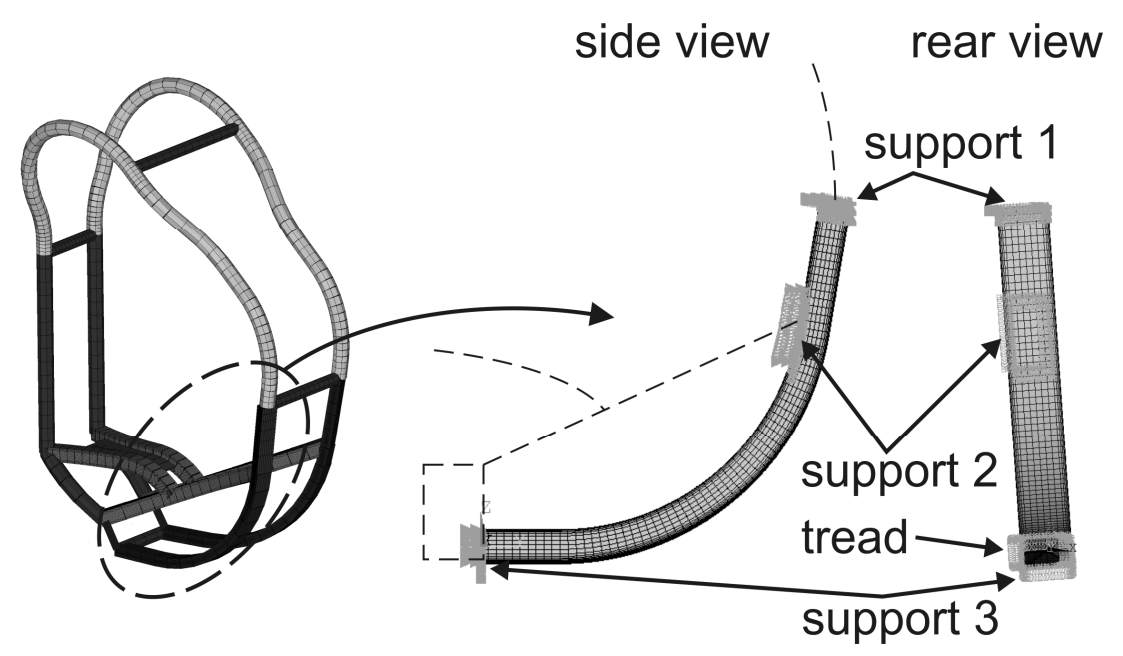

Fig. 2: Support of the profile in finite element model

Knowledge Based Model. Based on the knowledge acquisition described before, two submodels for a qualitative performance measure on residual stresses $P M_{r e s}$ in the profile were developed. The first model considers the effect of the welding chamber geometry which is mainly defined by the cross section. The second model takes the reinforced parts of the profile into account - the more reinforcement elements the higher the local residual stresses. Although residual stress investigations are available for aluminum profiles [21] (and with some restrictions also for reinforced profiles), the influence of the base material was not modeled due to lack of data and knowledge for extruded magnesium profiles. The inputs of the models are listed in Table 5.

\begin{tabular}{|l|l|l|l|}
\hline Model Nr. & Input 1 & Input 2 & Input 3 \\
\hline \hline 1 & $b_{\max } / b_{\min }$ & $H / B$ & $\begin{array}{l}\text { No. of chambers } \\
2 * N o_{\text {Stiffeners }}\end{array}$ \\
\hline 2 & $f_{1}$ & $f_{2}$ & - \\
\hline
\end{tabular}

Table 5: Input parameters for knowledge based models

In the first model, the welding chamber geometry is taken into account. $b_{\max } / b_{\min }$ has a high influence on the local residual stresses and $H / B$ has a medium influence. If the cross section has stiffeners and reinforcement, different material flows have to be joined in the die. This leads to chambers $\left(=2 * N o_{\text {Stiffeners }}\right)$ in the die which have a very high influence due to the longitudinal seam weld lines from the material flows. The resulting interaction $P M_{1}$ is shown for different numbers of chambers in Fig. 3. For each input three membership functions ('small', 'medium', 'large') are utilized resulting in 27 rules. The output has eleven membership functions in order to model the increase of residual stresses for a high chamber count. 


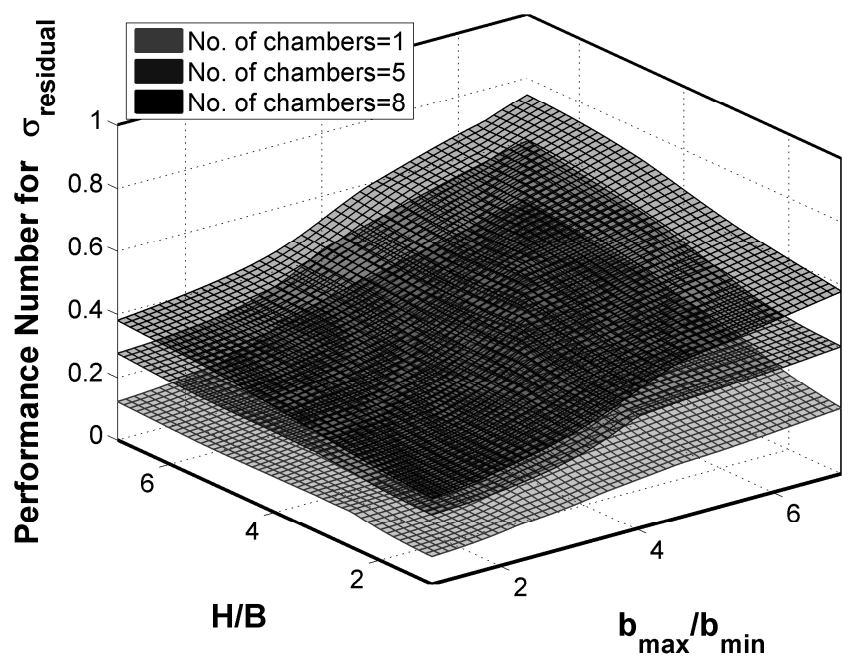

Fig. 3: Knowledge based model for performance measure $P M_{1}$ - influence of welding chamber geometry

In the second model the two different reinforcement ratios, $f_{1}$ and $f_{2}$, are equally important. The local residual stresses around one reinforcing element (steel wire, carbon fiber rope) are high. The stresses decrease rapidly with increasing distance from the reinforcement, but for high reinforcement ratios, these local residual stress fields can overlap. For the homogenized material parameters only qualitative estimations are possible. The overall performance measure $P M_{r e s}$ is calculated according to the following formula:

$$
P M_{\text {res }}=a_{1} * P M_{1}+a_{2} * P M_{2} \quad a_{1}=a_{2}=1 .
$$

The weighting factors $a_{i}$ could be used to change the influence of the to sub models on $P M_{\text {res }}$. In this example they were set to 1 because both aspects, the geometry of the welding chamber due to the profile cross section and the influence of the reinforcing elements, are assumed to have the same significance. The models are programmed in the MATLAB ${ }^{\circledR}$ Fuzzy Logic Toolbox.

Optimization algorithm. The genetic algorithm GAME (Genetic Algorithm for Multicriteria Engineering) is used to solve the optimization problem. An overview can be found in [22], a detailed description in [23]. The performance of GAME is comparable to the well known NSGA-II [24] (iSIGHT-FD implementation). The settings for the optimization algorithm are listed in

Table 6. They were chosen according to the available computation time and the problem dimensionality. Convergence plots of the goals also showed that in the last five generations only minimal improvements were achieved, indicating that the solution had converged.

5760 and 5790 system evaluations were performed by GAME for the 2-goals and 3-goals optimizations respectively. The computation time on a 17-node cluster (8GB RAM, Intel ${ }^{\circledR}$ Xeon $51603 \mathrm{GHz}$ each) was $24.5-33$ hours depending on the overall workload of the cluster. 


\begin{tabular}{|c|c|c|c|c|c|c|}
\hline $\begin{array}{c}\text { Population } \\
\text { Size }\end{array}$ & Generations & $\begin{array}{c}\text { Number of } \\
\text { Children }\end{array}$ & $\begin{array}{c}\text { Elite } \\
\text { Size }\end{array}$ & $\begin{array}{c}\text { Size of } \\
\text { NonDom. }\end{array}$ & $\begin{array}{c}\text { Mutation } \\
\text { Probability }\end{array}$ & $\begin{array}{c}\text { Standard } \\
\text { Deviation }^{2}\end{array}$ \\
\hline \hline 100 & 30 & 200 & 5 & 300 & $80 \%$ & $15 \%$ \\
\hline $\begin{array}{l}{ }^{1} \text { size of non dominated individuals storage } \\
{ }^{2} 1^{\text {st }} \text { gen., linearly decreased with increasing no. of generations }\end{array}$ \\
\hline
\end{tabular}

Table 6: Optimization settings for the genetic algorithm GAME

Results. In Fig. 4, the Pareto-optimal solutions of the 2-goals and 3-goals optimization runs are shown in the 'mass-deflection' plane. For a wide range of the Pareto-front, the designs have a similar mass and deflection performance. The 2-goals optimization generates better results only for very light designs. The designs $2 \mathrm{G}_{1}, 2 \mathrm{G}_{2}$ and $3 \mathrm{G}_{1-4}$ represent different possible solutions. Their corresponding cross sections are displayed on the right side of Fig. 4.
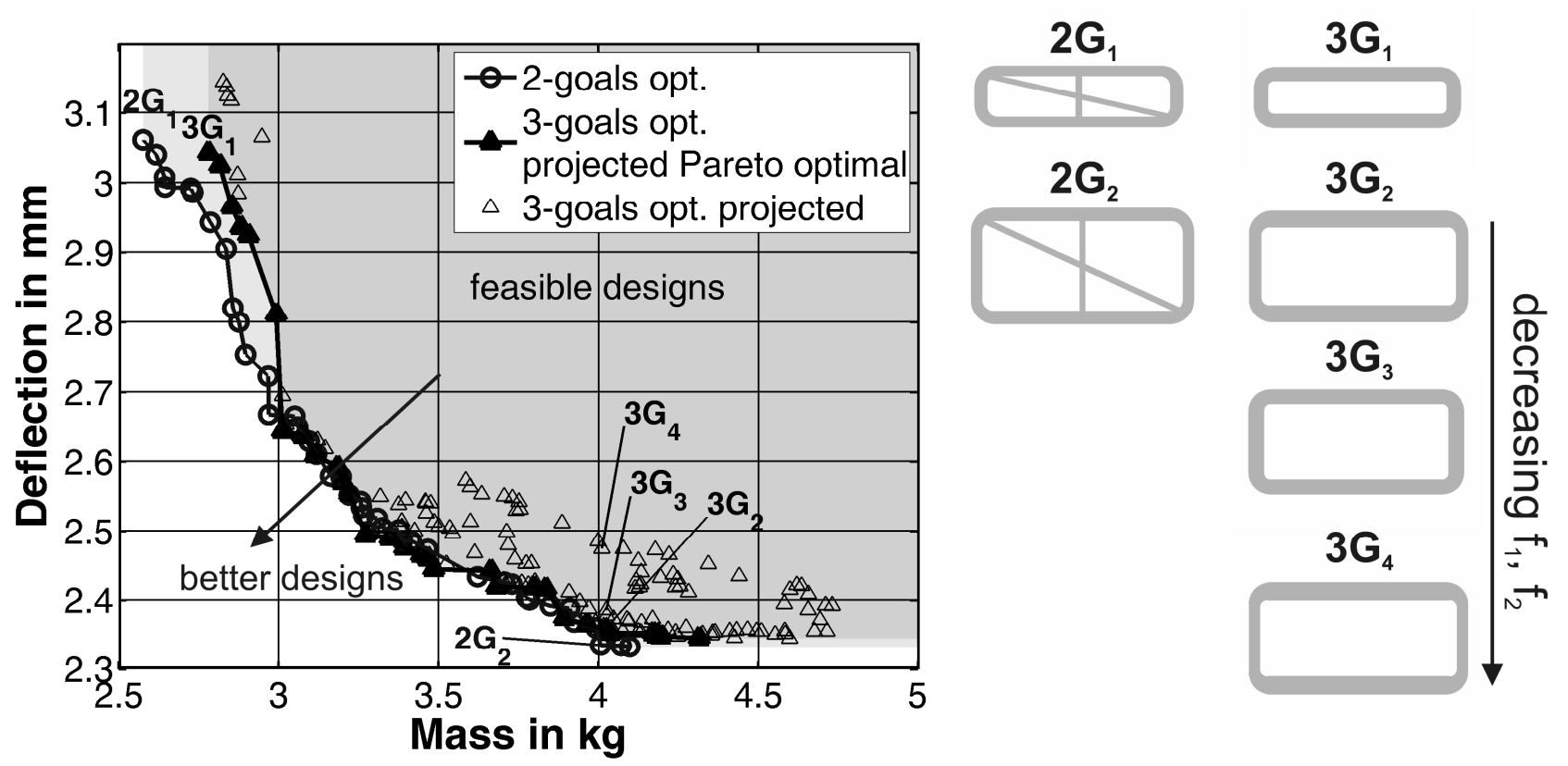

Fig. 4: Result of the 2-goals and 3-goals optimization in 'mass-deflection' plane

In Table 7, the design variables and the goals of the highlighted solutions are listed. All profiles are made of Magnesium with carbon fiber reinforcement (material and actual manufacturing cost were not considered!) and the width $B$ is at its upper boundary. Design $2 \mathrm{G}_{1}$ and $3 \mathrm{G}_{1}$ have small masses and large deflections. This is caused by a very small height, $H$, which is approximately half the height of the other designs. In the 2-goals optimization, a two-stiffener design for all Paretooptimal solutions evolved during the optimization run. To reach similar mechanical performance without stiffeners, the design $3 \mathrm{G}_{1}$ has a higher reinforcement ratio $f_{2}$ in the vertical walls of the cross section. This indicates that, with regard to the local residual stresses, a simple hollow profile with a higher reinforcement ratio has better results than a multi-chambered cross section.

Designs $2 \mathrm{G}_{2}$ and $3 \mathrm{G}_{2}$ have a very small deflection of less then $2.4 \mathrm{~mm}$. Taking the local residual stress performance measure into account, a higher overall reinforcement ratio and considerably different maximum and minimum wall thickness are preferable to a complex multi stiffener layout. Design $3 \mathrm{G}_{3}$ has only slightly worse mechanical properties but a much smaller $P M_{\text {res }}$. The lowest local residual stresses are predicted for design $3 \mathrm{G}_{4}$ which has no reinforcement at all. This good suitability for subsequent manufacturing processes comes with a $\sim 5 \%$ higher deflection. 


\begin{tabular}{|l|c|r|r|r|r|r|r|}
\hline Parameter & Unit & \multicolumn{1}{c|}{$2 \mathrm{G} 1$} & \multicolumn{1}{c|}{$2 \mathrm{G} 2$} & \multicolumn{1}{c|}{$3 \mathrm{G} 1$} & \multicolumn{1}{c}{$3 \mathrm{G} 2$} & \multicolumn{1}{c|}{$3 \mathrm{G} 3$} & \multicolumn{1}{c|}{3 4 } \\
\hline \hline$R$ & {$[1]$} & 0.697 & 0.109 & 0.269 & 0.048 & 0.000 & 0.000 \\
\hline$H$ & {$[\mathrm{~mm}]$} & 23.400 & 48.200 & 22.100 & 45.700 & 45.200 & 44.400 \\
\hline$B$ & {$[\mathrm{~mm}]$} & 90.000 & 99.200 & 91.100 & 100.000 & 100.000 & 98.300 \\
\hline$b_{1}$ & {$[\mathrm{~mm}]$} & 4.700 & 6.200 & 6.600 & 8.100 & 7.300 & 8.600 \\
\hline$b_{2}$ & {$[\mathrm{~mm}]$} & 6.000 & 5.200 & 6.800 & 5.900 & 7.800 & 5.200 \\
\hline$b_{3}$ & {$[\mathrm{~mm}]$} & 3.000 & 2.600 & - & - & - & - \\
\hline$b_{4}$ & {$[\mathrm{~mm}]$} & - & - & - & - & - & - \\
\hline$b_{5}$ & {$[\mathrm{~mm}]$} & - & - & - & - & - & - \\
\hline$b_{6}$ & {$[\mathrm{~mm}]$} & 2.500 & 2.800 & - & - & - & - \\
\hline$f_{1}$ & {$[\%]$} & 1.8 & 3.1 & 1.7 & 22.8 & 15.3 & 0.0 \\
\hline$f_{2}$ & {$[\%]$} & 6.0 & 5.4 & 16.3 & 12.1 & 7.6 & 0.0 \\
\hline Mat. $M$ & - & $\mathrm{Mg} / \mathrm{CF}$ & $\mathrm{Mg} / \mathrm{CF}$ & $\mathrm{Mg} / \mathrm{CF}$ & $\mathrm{Mg} / \mathrm{CF}$ & $\mathrm{Mg} / \mathrm{CF}$ & $\mathrm{Mg} / \mathrm{CF}$ \\
\hline Mass & {$[\mathrm{kg}]$} & 2.618 & 4.007 & 2.781 & 4.021 & 4.025 & 4.011 \\
\hline Deflection & {$[\mathrm{mm}]$} & 3.040 & 2.335 & 3.042 & 2.358 & 2.386 & 2.474 \\
\hline PM res & {$[1]$} & - & - & 0.492 & 0.560 & 0.484 & 0.349 \\
\hline
\end{tabular}

Table 7: Design variables and goals of six selected designs of the solution

In Fig. 5, the Pareto-optimal solutions of the 3-goals optimization are given for the other two projections of the three goals. Whereas the left diagram provides basically the same information as Fig. 4, the right diagram 'Performance Measure over Mass' clearly indicates the jump from profiles with low local residual stresses to profiles with high local residual stresses for designs with a mass less then $3 \mathrm{~kg}$.
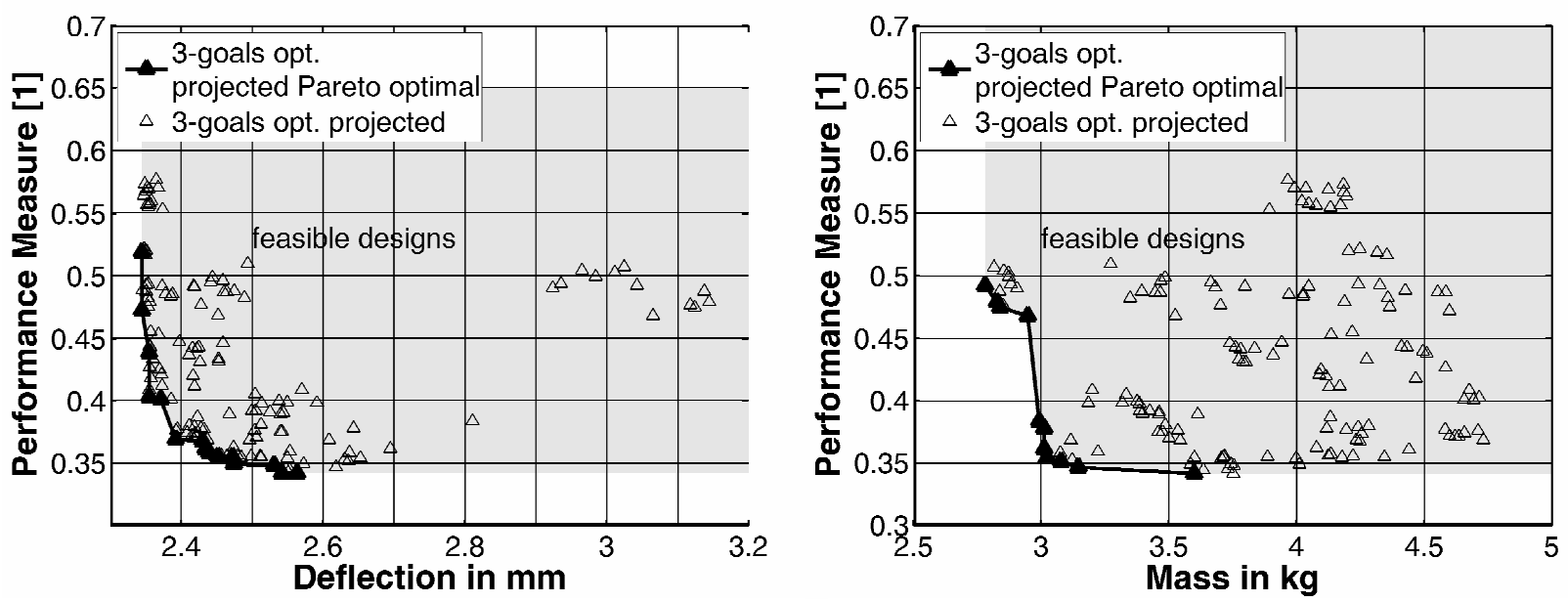

Fig. 5: Results for the 3-goals optimization projected to different planes

The different optimal designs also have different limiting constraints $\left(g_{i} \leq 0\right)$, which are shown in Fig. 6. The curves are related to the minimum and maximum mass profile respectively. For the 2goals optimization, the minimum mass design is restricted by the deformation in the first load case, $u_{L F 1}$, and the stresses perpendicular to the embedded continuous reinforcing elements in load cases 1 and $2\left(\sigma_{1 \perp}, \sigma_{2 \perp}\right)$. The maximum mass design is limited by $u_{L F 1}$ and the two buckling constraints for $\lambda_{2}$ and $\lambda_{3}$. The latter indicates an unfavorable thermal deformation behavior for such profiles. 
For the 3-goals optimization, the minimum mass design is restricted by $u_{L F 1}, \sigma_{2 \perp}$ and $\lambda_{2}$ whereas the maximum mass design is restricted by the first eigenfrequency $\omega_{1}$ and $u_{L F 1}$.

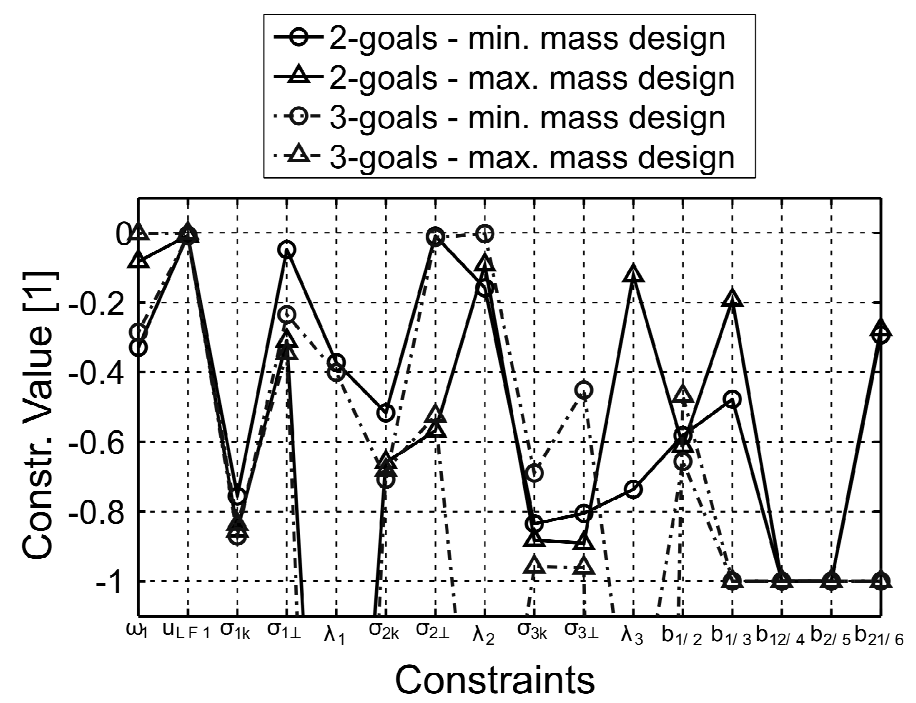

Fig. 6: Constraints for the min./max. mass designs of the 2-goals and 3-goals optimization

\section{Summary}

In this paper, the authors investigate a method to implement qualitative knowledge into multiobjective optimization problems. With the help of knowledge acquisition techniques, fuzzy models are built for influences for which little or no simulation or test data is available. The method is demonstrated on the optimization of an extruded hollow profile in a vehicle space frame. The manufacturing of reinforced, curved aluminum and magnesium profiles leads to local residual stresses, which are unfavorable for subsequent manufacturing processes, and can't be eliminated by a heat treatment. A qualitative performance measure for the residual stresses is approximated with the help of expert knowledge.

The described optimization runs showed the benefits of the approach. A 2-goals optimization for just the mechanical performance resulted in complex profile cross sections. The optimal designs of a 3-goals optimization, also taking into account the qualitative residual stress performance, have similar mechanical performance but considerably better predictions for the local residual stresses. Reinforcement is preferred to the use of stiffeners.

The knowledge based approximation models can provide only a rough estimation and further investigations are necessary to take these uncertainties into account during the optimization process. This affects not only the approximation model itself, but also the optimization algorithm. The proposed method is a promising complement to other soft computing techniques utilized in early product development stage optimization.

\section{Acknowledgment}

This paper is based on investigations of the collaborative research center SFB/TR10 which is kindly supported by the German Research Foundation (DFG). 


\section{References}

[1] J. Hirsh, P. Hajela, J.C. Spering, G.A. Coen, E. Mytych: MADEsmart: An Environment for Improved Development of Aircraft Components in Preliminary Design, Engineering with Computers, Vol. 17 No. 2, pp 162-185, 2001

[2] O. de Weck, J. Agte, J. Sobieszczanski-Sobieski, P. Arendsen, A. Morris, M. Spieck: State-ofthe-Art and Future Trends in Multidisciplinary Design Optimization, 48th AIAA/ASME/ASCE/AHS/ASC Structures, Structural Dynamics, and Materials Conference, Waikiki Honolulu, Hawaii, 2007

[3] J.T. Alander: Empirical comparison of stochastic algorithms, Proceedings of the Second Nordic Workshop on Genetic Algorithms and their Applications, Vaasa, Finland, 1996

[4] A. Giassi, F. Bennis, J.J. Maisonneuve: Multidisciplinary design optimisation and robust design approaches applied to concurrent design, Structural and Multidisciplinary Optimization, Vol. 28 No. 5, pp 356-371, 2004

[5] R. Jin, W. Chen, T.W. Simpson: Comparative studies of metamodelling techniques under multiple modelling criteria, Structural and Multidisciplinary Optimization, Vol. 23 No. 1, pp $1-13,2001$

[6] F. Paulsen, T. Welo: A design method for prediction of dimensions of rectangular hollow sections formed in stretch bending, Journal of Materials Processing Technology, Vol. 128 No. 1-3, pp 48-66, 2002

[7] B.L. Subramaniam, K.T. Ulrich: Producibility Analysis Using Metrics Based on Physical Process Models, Research in Engineering Design, Vol. 10 No. 4, pp 210-225, 1998

[8] M. Kleiner, A. Klaus, M. Schomäcker: Composite Extrusion - Determination of the Influencing Factors on the Positioning of the Reinforcing Elements, Advanced Materials Research: Flexible Manufacture of Lightweight Frame Structures, Vol. 10, pp 13-22, 2006

[9] M. Schikorra, M. Kleiner: Seam Weld Positioning for Composite Extrusion, Advanced Materials Research: Flexible Manufacture of Light Weight Frame Structures, Vol. 10, pp 100110,2006

[10] S.H. Hsiang, J.L. Kuo: Applying ANN to predict the forming load and mechanical property of magnesium alloy under hot extrusion, The International Journal of Advanced Manufacturing Technology, Vol. 26 No. 9-10, pp 970-977, 2005

[11] P. Hajela: Soft computing in multidisciplinary aerospace design - new directions for research, Progress in Aerospace Sciences, Vol. 38, pp 1-21, 2002

[12] L.A. Zadeh: Fuzzy Sets, Information and Control, Vol. 3 No. 8, pp 338-353, 1965

[13] M. Huber, H. Baier: Qualitative Knowledge and Manufacturing Considerations in Multidisciplinary Structural Optimization of Hybrid Material Structures, Advanced Materials Research, Vol. 10, pp 143-152, 2006

[14] B. Schaible, Y.C. Lee: Fuzzy Logic Based Regression Models for Electronic Manufacturing Applications, Advances in Electronic Packaging 1997 - Proceedings of the Pacific Rim/ASME International Intersociety Electronic \& Photonic Packaging Conference (INTERPack '97), Kohala Coast, Hawaii, pp 147-155, 1997

[15] R. Gleichmar: Approximationen und paralleles Rechnen bei der multidisziplinären Strukturoptimierung, PhD Thesis - Technische Universität München, URN: urn:nbn:de:bvb:91diss20050628-1119013588, 2004 
[16] S.M. Taheri: Trends in Fuzzy Statistics, Austrian Journal of Statistics, Vol. 32 No 3, pp 239257,2003

[17] L. Rutkowski: Flexible Neuro-Fuzzy Systems, IEEE Transactions on Neural Networks, Vol. 14 No. 3, 2003

[18] R.R. Hoffman, R.N. Shadbolt, M.A. Burton, G. Klein: Eliciting knowledge from Experts: A methodological analysis, Organizational behavior and human decision processes, Vol. 62 No. 2, pp 129-158, 1995

[19] P.W. Wagner, L.M. Zubey: Knowledge acquisition for marketing expert systems based upon marketing problem domain characteristics, Marketing Intelligence \& Planning, Vol. 23 No. 4, pp 403-416, 2005

[20] A. Klaus, D. Becker, M. Kleiner: Three-Dimensional Curved Profile Extrusion - First Results on the Influence of Gravity, Advanced Materials Research: Flexible Manufacture of Lightweight Frame Structures, Vol. 10, pp 5-12, 2006

[21] D. Becker, M. Schomäcker, A. Klaus, M. Kleiner: Alternative Manufacture of Curved Profiles for Automotive and Railway Lightweight Constructions, Proceedings of the 1st International Conference 'Aluminium in Transport', Moscow, Russia, 2005

[22] H. Langer, T. Pühlhofer, H. Baier: A Multiobjective Evolutionary Algorithm with Integrated Response Surface Functionalities for Configuration Optimization with Discrete Variables, Proceedings 10th AIAA/ISSMO Multidisciplinary Analysis and Optimization Conference, Albany, New York, USA, 2004

[23] H. Langer: Extended Evolutionary Algorithms for Multiobjective and Discrete Design Optimization of Structures, PhD Thesis - Technische Universität München\}, URN: urn:nbn:de:bvb:91-diss20061108-1512163206, 2005

[24] K. Deb, A. Pratab, S. Agarwal, T. Meyarivan: A fast and elitist multiobjective genetic algorithm: NSGA-II, IEEE Transactions on Evolutionary Computation, Vol. 6 No. 2, pp 182197, 2002 